\title{
Preparation and Luminescence Properties of Europium(III) Ternary Complex-modified Poplar Wood-based Materials
}

\author{
Kong Fanrua , Huang Rui ${ }^{a}$,Wang Di ${ }^{a}{ }^{\star D}$, Li Jian ${ }^{a}$ \\ ${ }^{a}$ Material Science and Engineering College, Northeast Forestry University, Harbin, Heilongjiang, China
}

Received: November 05, 2018; Revised: May 14, 2019; Accepted: June 29, 2019

Inspired by the ultraviolet induced properties of biological materials, we developed fluorescent wood as a new type of functional material which can be applied to anti-counterfeit label technology and wood-emitting artwork. This study discusses the influence of temperature, time, ligand ratio, and reactant concentration on the structure and properties of fluorescent wood with europium(III) ternary complexes. The surface morphology and fluorescent properties of the modified wood were characterized by scanning electron microscopy (SEM) and fluorescence spectrometry. The results showed that a high reaction temperature of $75^{\circ} \mathrm{C}$ was beneficial in obtaining stronger fluorescent wood; a reaction time of $8 \mathrm{~h}$ exerted a significant influence on fluorescent wood when the reactant concentration of the sample was $0.03 \mathrm{~mol} / \mathrm{L}$. In addition, the results of infrared spectroscopy, X-ray photoelectron spectroscopy, and energy-dispersive X-ray analysis showed that modification of wood takes place through the $\mathrm{Si}-\mathrm{OH}$ groups of the silane coupling agent, which link to the surface of wood. After 120 hours of UV light irradiation, the surface fluorescence intensity of the modified wood can reach 500 arb. units. It can be considered that the modified wood has better anti-ultraviolet aging properties, thereby prolonging the life of poplar.

Keywords: Fluorescent, europium ternary complexes, silane-modified, poplar wood-based materials.

\section{Introduction}

Wood is a carbon-neutral material and hence does not result in a net increase in carbon dioxide due to cyclic carbon fixation during photosynthesis and degradation ${ }^{1}$. Apart from usage in houses, furniture, artwork, heating, and decoration, wood and its derivative materials are also widely used in green electronics ${ }^{2,3}$. With continuous development in the field of materials science, wood materials are increasingly being considered as biological templates with new properties ${ }^{4}$. In recent years, many approaches for modifying wood surfaces have been proposed, such as magnetic biochar based on wood ${ }^{5}$. There are many studies on the production of superhydrophobic wood materials ${ }^{6,7}$. Nowadays, only a few wood types are being used as templates for the preparation of luminescent materials ${ }^{8}$. It is well known that europium-based fluorescent complexes, which are red-light emitting phosphor materials, exhibit long luminescence lifetimes and sharp emission bands ${ }^{9}$.

The surface of the wood-based material has a large number of reactive functional groups, and grafting reaction can occur between the functional materials. The organic-inorganic hybrid wood-based fluorescent material with excellent performance, which not only realizes the light functionalization of wood, but also can be used for the construction of surface patterns of wood products, design of new wooden-based anti-counterfeit labels and exhibition of wooden art. The advantages of phosphor materials extracted from wood biotemplates may be of significant benefit in anisotropic structures, when combined with prospective lightguide properties ${ }^{10}$.
In order to broaden the application of wood as a template material for optical functionality, this study describes a type of modified wood synthesized with europium ternary complexes; these modified woods, unlike untreated wood, exhibit fluorescence. To analyze the chemical nature of such fluorescent wood, several analytical techniques, were employed. It was found from our analysis that the developed fluorescent wood surfaces can prevent wood components from being destroyed by UV light and hence their life can be extended.

\section{Methods}

\subsection{Materials and sample preparation}

Ethanol (99.7\%) and methylene dichloride (analytical grade) were provided by Tianjin Kaitong Chemical Reagent Co., Ltd. (China). Phthaloyl chloride (98\%), aminopropyl trimethoxysilane (KH550), and $\mathrm{Eu}\left(\mathrm{NO}_{3}\right)_{3} 6 \mathrm{H}_{2} \mathrm{O}(99.99 \%)$ were procured from Beijing Huaweiruike Co., Ltd. (China), while hydrochloric acid was supplied by Yantai Double Chemical Co., Ltd. (China).

Beams of poplar sapwood $(10 \mathrm{~mm} \times 5 \mathrm{~mm} \times 2 \mathrm{~mm})$ were obtained from Linbang Wood Industry Board Factory, ShanDong, China. The samples were impregnated by ultrasonic washing for $10 \mathrm{~min}$ with acetone, ethanol, and deionized water (in sequence) and then dried at $80^{\circ} \mathrm{C}$ in a vacuum oven for $2 \mathrm{~h}$. 


\subsection{Synthesis of the modified complexes}

Phthaloyl chloride $(0.001 \mathrm{~mol})$ in methylene chloride $(10 \mathrm{~mL})$ was added to a solution of aminopropyl triethoxysilane $(0.002 \mathrm{~mol})$ in methylene chloride $(10 \mathrm{~mL})$ at $0{ }^{\circ} \mathrm{C}$. Triethylamine was added to the reaction mixture and stirred at room temperature for 2 h. After washing and purification, a yellow viscous liquid of the modified ligand was obtained, as is showed in Fig. 1. The modified ligand, 1,10-phenanthroline, and $\mathrm{Eu}\left(\mathrm{NO}_{3}\right)_{3} \cdot 6 \mathrm{H}_{2} \mathrm{O}$ were accurately weighed at pre-determined quantities and dissolved in $10 \mathrm{~mL}$ of anhydrous ethanol. The complexes were heated continuously under reflux at different temperatures $\left(35,45,55,65\right.$, and $\left.75^{\circ} \mathrm{C}\right)$ for different time periods $(4,6$, $8,10$, and $12 \mathrm{~h})^{11}$. Later, the mixtures were dried in an oven at $80{ }^{\circ} \mathrm{C}$ for $12 \mathrm{~h}$. (See the Fig. 2)

\subsection{Synthesis of fluorescent wood}

The infiltration solutions were prepared by dissolving the modified complexes in ethanol at different concentrations $(0.005,0.0075,0.01,0.0125,0.015,0.02,0.03$, and 0.04 $\mathrm{mol} / \mathrm{L})$. The wood to be treated was placed in the desired solution to which a few drops of dilute hydrochloric acid were added and then stirred at $70{ }^{\circ} \mathrm{C}$ for $4 \mathrm{~h}$. Finally, the wood samples were placed in a vacuum drying oven and dried at $120^{\circ} \mathrm{C}$ for $30 \mathrm{~min}$.

\section{Characterization}

The elemental compositions of the wood samples were determined by IR spectroscopy (FT-IR, Magna-560, Nicolet) and XPS analysis (PHI Thermo Fisher Scientific Company Quantera). Thermogravimetric analysis (TGA) was performed on a thermal analyzer (Q500, American TA Company) in an inert $\left(\mathrm{N}_{2}\right)$ environment at a heating rate of $10{ }^{\circ} \mathrm{C} / \mathrm{min}$ between ambient temperature and $800{ }^{\circ} \mathrm{C}$. The infiltrated wood samples and native wood samples were transferred onto a sample holder for SEM analysis and sputtered with gold (Quanta 200, FEI, Hillsboro, Oregon).

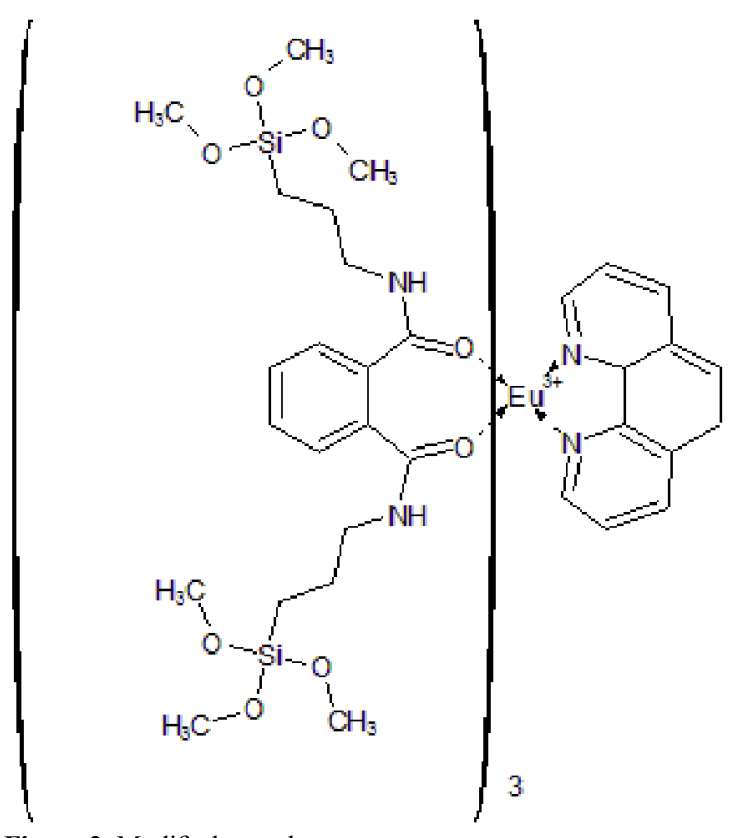

Figure 2. Modified complex structure

Luminescence spectra were recorded at room temperature using a LS55 fluorescence spectrometer. The excitation and emission monochromator slit widths were $10 \mathrm{~nm}$ and $5 \mathrm{~nm}$, respectively, and the speed was set at $600 \mathrm{~nm} / \mathrm{min}$. The wettability of the solid surfaces was measured using an optical contact angle meter with $5 \mu \mathrm{L}$ deionized water droplets at room temperature.

\section{Results and Discussion}

\subsection{The formation of chemical bonds on wood.}

The phthalyl chloride reacts with KH550 to form a modified ligand. The $\mathrm{C}=\mathrm{O}$ in the modified ligand and the $\mathrm{N}$ in 1,10-phenanthroline coordinate with the central ion $\mathrm{Eu}^{3+}$ to form a silane modification complex.<smiles>O=C(Cl)c1ccccc1C(=O)Cl</smiles><smiles>[I-][I-]</smiles>

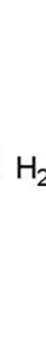

Figure 1. Modified ligand structure<smiles>CCO[Si](CCCNC(=O)c1ccccc1C(=O)NCCC[Si](OCC)(OCC)OCC)(OCC)OCC</smiles> 
The formation of chemical bonds on wood surfaces occurs due to modification with rare earth complexes $\left(-\mathrm{Si}_{-}-\mathrm{OC}_{2} \mathrm{H}_{5}\right.$ groups) in acid hydrolysis conditions, which generates a large number of $\mathrm{Si}-\mathrm{OH}$ groups ${ }^{12}$. The $\mathrm{Si}-\mathrm{OH}$ groups are absorbed by the wood surface and penetrate the fibers due to the porous nature of wood ${ }^{13}$. Si-OH groups can efficiently undergo a self-condensation reaction to form Si-O-Si bonds. Therefore, after condensation polymerization under heating conditions, modified rare earth complexes are combined with wood surfaces by covalent bonds ${ }^{14}$ (see the Fig. 3).

\subsection{EDX analysis}

EDX patterns of native wood indicate a composition consisting of $61.42 \% \mathrm{C}$ and $38.58 \% \mathrm{O}$. In contrast, the modified fluorescent wood (By impregnated with 1:3:1 modified complex) also included $9.65 \% \mathrm{Si}$ and $11.95 \%$ Eu. The mass ratio of silicon and europium is 0.81 , while the material ratio of reactions is 1.1 . The ligand modified by the silane coupling agents does not adequately react with europium ions. The modified fluorescent wood samples show an absorption peak corresponding to silicon at $1.84 \mathrm{keV}$ and atomic europium at $5.9 \mathrm{keV}$. Meanwhile, the absorption peak of atomic chlorine at $2.63 \mathrm{keV}$ could be ascribed to the presence of dilute hydrochloric acid that could accelerate hydrolysis (see the Fig. 4).

\subsection{IR analysis}

Fig. 5 depicts the IR spectra $\left(4000-400 \mathrm{~cm}^{-1}\right)$ of native wood and modified wood samples. The absorption peaks at $1031 \mathrm{~cm}^{-1}$ and $2910 \mathrm{~cm}^{-1}$ are attributed to cellulose, while the peak at $1736 \mathrm{~cm}^{-1}$ is attributed to hemicellulose ${ }^{15-17}$. The -OH group vibration at $3350 \mathrm{~cm}^{-1}$ and benzene carbon skeleton absorption peak near $1505 \mathrm{~cm}^{-1}$ in Fig. 5(a) can be observed to be different from those in Fig. 5(b).

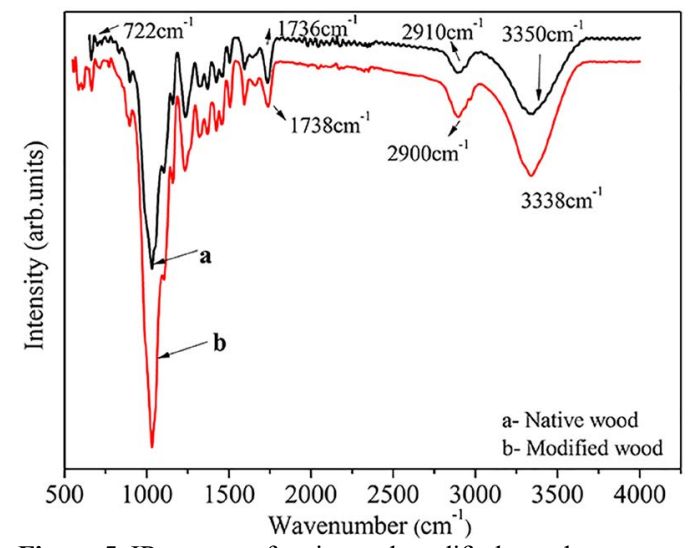

Figure 5. IR spectra of native and modified wood<smiles>[R1][Si](O)(O)[Si]([R1])(O)O</smiles>

Figure 3. The formation of chemical bonds on wood

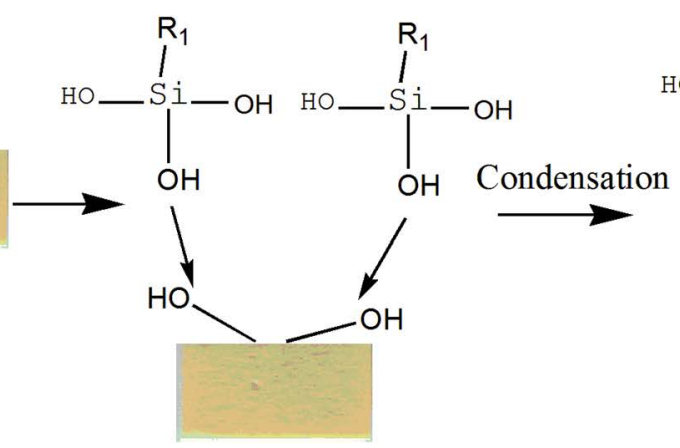

Wood

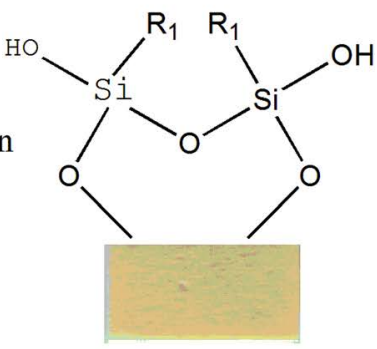

Wood
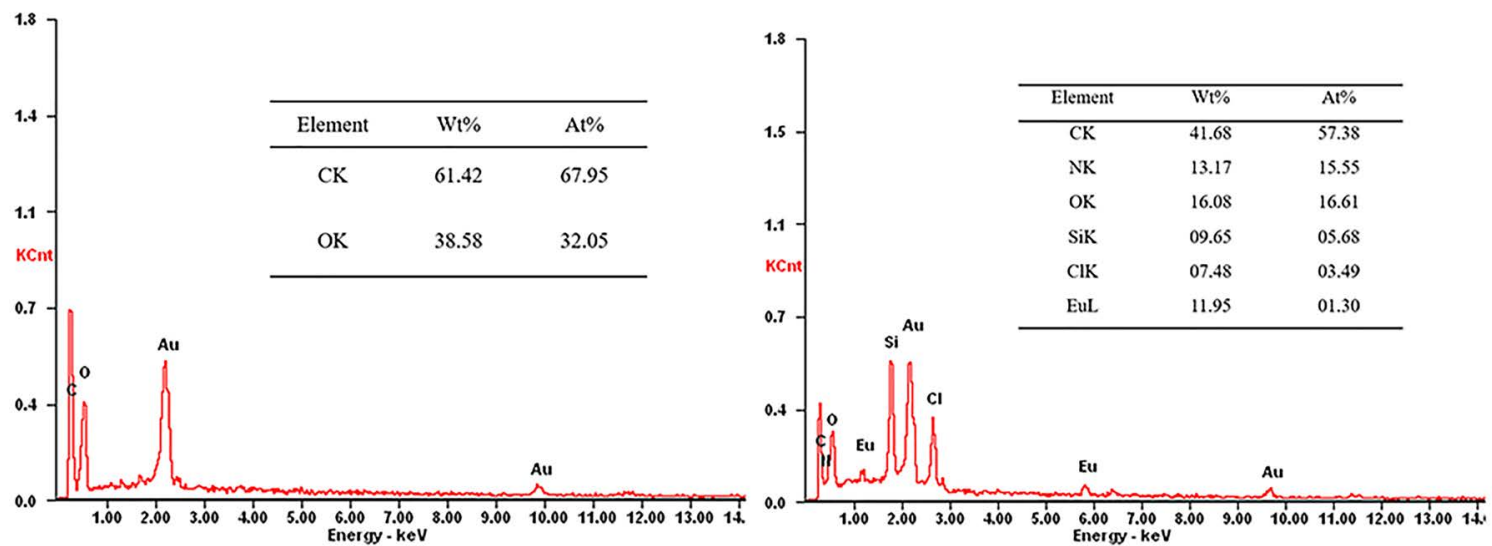

Figure 4. EDX analysis of native wood(a) and modified fluorescence wood(b) 
The characteristic absorption peak at $3338 \mathrm{~cm}^{-1}$ shifted to a high wavenumber, which corresponds to a change in the density of the electron cloud; this change is responsible for the weakening of $\sigma$ covalent bonds and induces a red shift in the characteristic absorption peak. The absorption peak at 722 $\mathrm{cm}^{-1}$ can be assigned to the stretching vibrations of the $\mathrm{Si}-\mathrm{C}$ bonds of siloxane components. The typical absorption peaks of Si-O-Si bonds of siloxane components appearing at 1031 $\mathrm{cm}^{-1}$ overlap with the characteristic peaks of cellulose ${ }^{18,19}$. Analysis of the spectra confirmed the presence of silicon atoms on the surface of the wood samples.

\subsection{XPS analysis}

To further gather molecular-level information on Eu(III) adsorbed onto wood, XPS measurements were conducted for the surface-elemental analysis of 1,10-phenanthroline,modified ligand, native wood, modified complexes, and modified wood. The average binding energies of $\mathrm{C}_{1 \mathrm{~s}}, \mathrm{O}_{1 \mathrm{~s}}, \mathrm{~N}_{1 \mathrm{~s}}, \mathrm{Si}_{2 \mathrm{p}}$, and $\mathrm{Eu}_{3 \mathrm{~d}}$ are listed in Table 1. As shown in Fig. 6(a), two major peaks of $\mathrm{C}$ and $\mathrm{O}$ are clearly distinguishable, indicating that the native wood was mainly composed of $\mathrm{C}$ (66.5 at.\%) and $\mathrm{O}$ (33.5 at.\%).

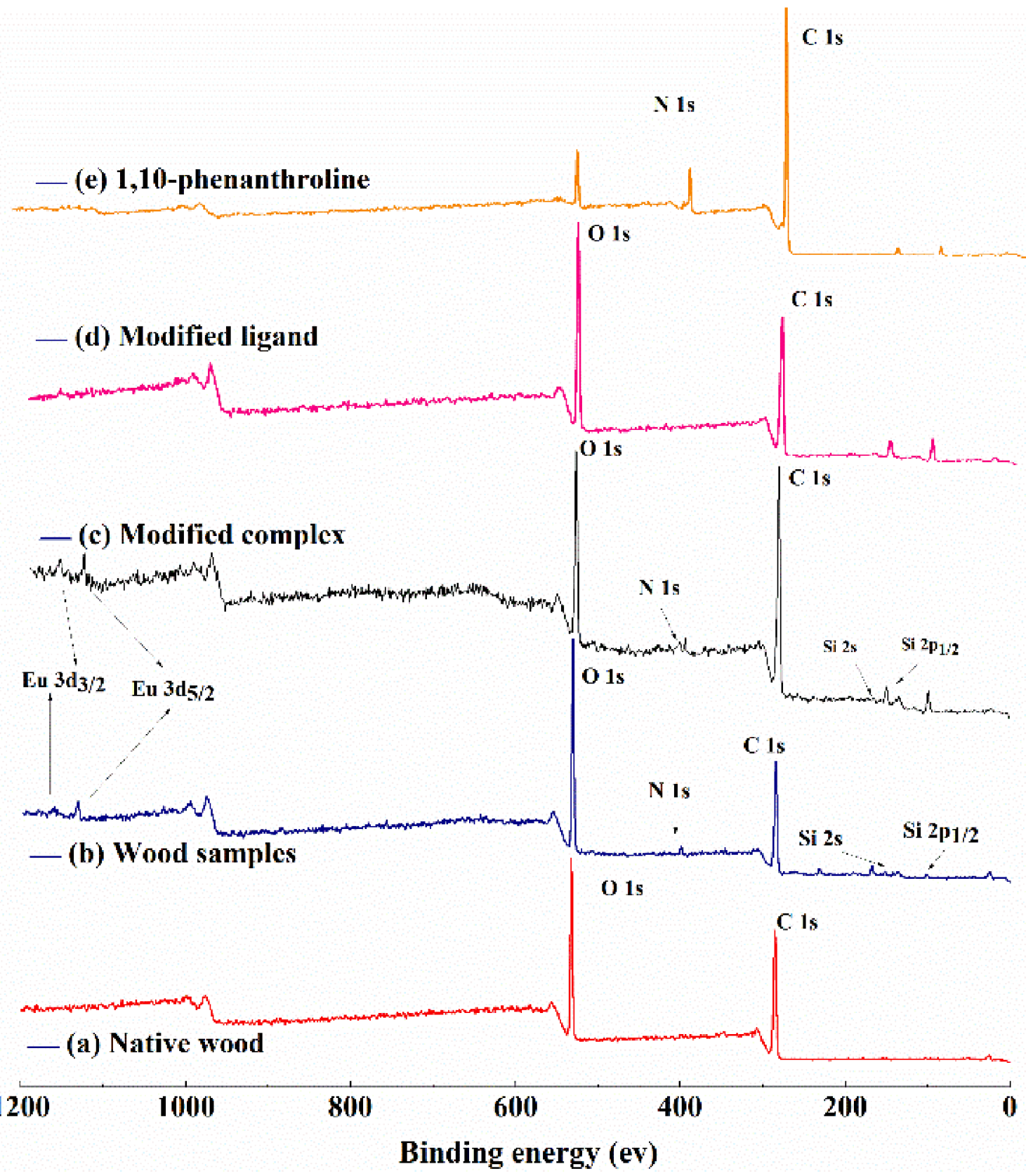

Figure 6. XPS survey spectra (a) native wood, (b) modified w ood, (c) modified complexes,(d) modified ligand and (e) 1,10-phenanthroline 
The average binding energies of $\mathrm{C}_{1 \mathrm{~s}}, \mathrm{O}_{1 \mathrm{~s}}, \mathrm{~N}_{1 \mathrm{~s}}, \mathrm{Si}_{2 \mathrm{p}}$, and $\mathrm{Eu}_{3 \mathrm{~d}}$ in the modified wood increased by $0.96,0.85,2.38,0.46$, and $1.14 \mathrm{eV}$, respectively, as compared to the modified complexes.

The bond energies of $\mathrm{N}_{1 \mathrm{~s}}$ and $\mathrm{O}_{1 \mathrm{~s}}$ in different samples are shown in Table 2. For 1,10-phenanthroline, the main peak at $397.6 \mathrm{eV}$ is assigned to the $\mathrm{N}$ element $(\mathrm{C}=\mathrm{N}-\mathrm{C})$ on the aromatic ring bonded to the $\mathrm{C}$ atom in the $\mathrm{sp}_{2}$ hybrid form. The second peak at $400.25 \mathrm{eV}$ is attributed to the $\mathrm{N}$ element $\left(\mathrm{H}-\mathrm{N}-\mathrm{C}_{2}\right)$ connected to the $\mathrm{C}$ atom in the $\mathrm{sp}_{3}$ hybrid form. The weakest peak at the binding energy of $404.8 \mathrm{eV}$ is due to the excitation of the $\pi$ electron cloud in the $\mathrm{N}$ element ${ }^{20}$; The binding energy of $\mathrm{N}_{1 \mathrm{~s}}$ of 1,10-phenanthroline and native wood was shifted toward the high binding energy direction. The formation of the modified complex involves the coordination of Eu-O and Eu-N, so the binding energy of both ligands $\mathrm{N}_{1 \mathrm{~s}}$ is shifted toward the high binding energy compared to the modified complex. The $\mathrm{O}_{1 \mathrm{~s}}$ binding energy of modified ligand, modified complexes and 1,10-phenanthroline was shifted toward the low binding energy direction compared with the modified wood. This is due to the efficient selfcondensation reaction of the $\mathrm{Si}-\mathrm{OC}_{2} \mathrm{H}_{5}$ groups in the complexes with the $-\mathrm{OH}$ groups on the surface of the wood to form Si-O-C groups, which led to a decrease in the electron density of the $\mathrm{O}$ atoms.

\subsection{Fluorescence spectroscopy}

\subsubsection{Ligand ratio of the sample}

The effect of the ligand on the fluorescent wood was determined by changing the ratio of 1,10-phenanthroline and the modified silane ligand, as shown in Table 3. These samples were heated for $4 \mathrm{~h}$ at $70^{\circ} \mathrm{C}$. When the molar ratio of 1,10-phenanthroline/ $\mathrm{Eu}^{3+}$ is $1: 1$, the ratio of $\mathrm{Eu}^{3+} /$ ligands peak intensity is equal to $1: 1$, the fluorescence emission of the 1:1:3 (Eu: 1,10-phenanthroline: silane ligand) complex is the strongest (see the Fig. 7).

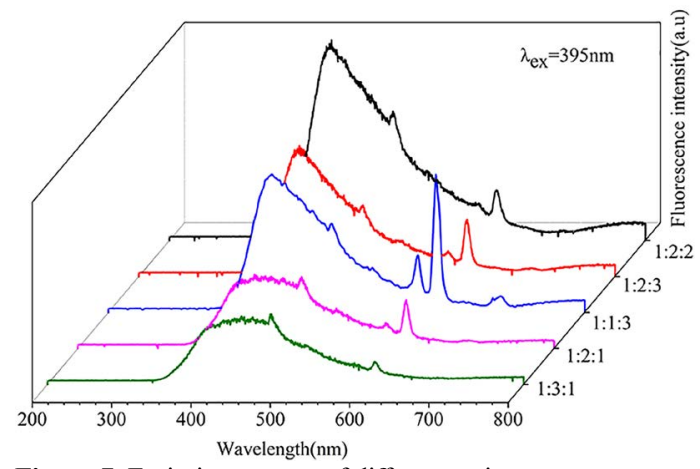

Figure 7. Emission spectra of different ratio

Table 1. The bonding energies of electrons $(\mathrm{eV})$ in different samples

\begin{tabular}{lccccc}
\hline Samples & $\mathrm{C}_{1 \mathrm{~s}}$ & $\mathrm{O}_{1 \mathrm{~s}}$ & $\mathrm{~N}_{1 \mathrm{~s}}$ & $\mathrm{Si}_{2 \mathrm{p}}$ & $\mathrm{Eu}_{3 \mathrm{~d}}$ \\
\hline Modified ligand & 284.28 & 531.86 & 405.21 & 101.49 & - \\
1,10-phenanthroline & 283.74 & - & 397.59 & - & - \\
Modified complexes & 283.69 & 530.87 & 398.53 & 101.42 & 1133.47 \\
Modified wood & 284.65 & 531.72 & 400.91 & 101.88 & 1134.61 \\
Native wood & 284.99 & 532.02 & - & - & - \\
\hline
\end{tabular}

Table 2. The bonding energies of $\mathrm{N}_{1 \mathrm{~s}}$ and $\mathrm{O}_{1 \mathrm{~s}}$ in different samples

\begin{tabular}{lccccc}
\hline Samples & \multicolumn{5}{c}{$\mathrm{N} 1 \mathrm{~s}(\mathrm{eV})$} \\
\hline Modified ligand & 405.20 & - & - & 531.50 & 532.50 \\
Modified complex & 406.60 & - & - & 531.30 & 532.30 \\
Modified wood & - & 400.96 & 399.80 & 531.20 & 532.00 \\
1,10 -phenanthroline & 404.80 & 400.25 & 397.61 & - & - \\
Native wood & - & - & 399.45 & 531.98 & - \\
\hline
\end{tabular}

Table 3. Preparation of different ratios of ligands/ $/ \mathrm{Eu}^{3+}$ ions $(0.01 \mathrm{~mol})$

\begin{tabular}{cccc}
\hline $\begin{array}{c}\text { Molar ratio of } \mathrm{Eu}^{3+}: 1,10- \\
\text { phenanthroline:modified ligand }\end{array}$ & $\mathrm{Eu}^{3+}$ peak intensity (I/arb.units) & Ligands peak intensity (I/arb.units) & Ratio of Eu $^{3+} /$ ligands \\
\hline $1: 2: 2$ & 58.201 & 247.051 & 0.236 \\
$1: 2: 3$ & 66.675 & 159.443 & 0.418 \\
$1: 1: 3$ & $\mathbf{1 6 8 . 6 0 8 6}$ & $\mathbf{1 6 8 . 8 9 7 2}$ & $\mathbf{0 . 9 9 8}$ \\
$1: 2: 1$ & 55.025 & 88.126 & 0.624 \\
$1: 3: 1$ & 23.527 & 80.755 & 0.291 \\
\hline
\end{tabular}




\subsubsection{The reactant concentration of the sample}

In order to investigate the fluorescent properties of the modified wood samples, their emission spectra were recorded in a homogeneous powder state at room temperature. Fig. 8 illustrates the spectra of wood samples containing 1:1:3 (Eu: phenanthroline: silane ligand) at different concentrations of $0.005,0.0075,0.01,0.0125,0.015,0.02,0.03$, and 0.04 $\mathrm{mol} / \mathrm{L}$; small differences in the peak intensities could be observed. Under UV irradiation with 395-nm light, the emission spectra of modified wood exhibited characteristic ${ }^{5} \mathrm{D}_{0} \rightarrow{ }^{7} \mathrm{~F}_{1},{ }^{5} \mathrm{D}_{0} \rightarrow{ }^{7} \mathrm{~F}_{2},{ }^{5} \mathrm{D}_{0} \rightarrow{ }^{7} \mathrm{~F}_{3}$, and ${ }^{5} \mathrm{D}_{0} \rightarrow{ }^{7} \mathrm{~F}_{4}$ electronic transitions at 590,614,650, and $686 \mathrm{~nm}$, respectively. The most intense peak at $614 \mathrm{~nm}$ was an induced electric dipole for the ${ }^{5} \mathrm{D}_{0} \rightarrow{ }^{7} \mathrm{~F}_{2}$ transition of $\mathrm{Eu}^{3+}$, which indicates that the complexes occupy a site of low symmetry surrounding the Europium ion ${ }^{21}$. In this situation, according to the Judd-Ofelt theory, the ${ }^{5} \mathrm{D}_{0} \rightarrow{ }^{7} \mathrm{~F}_{0}$ transition was forbidden and it was always absent or much weaker than ${ }^{5} \mathrm{D}_{0} \rightarrow{ }^{7} \mathrm{~F}_{1}$ and ${ }^{5} \mathrm{D}_{0} \rightarrow{ }^{7} \mathrm{~F}_{2}$ due to the same angular momentum ${ }^{22,23}$. And the ${ }^{5} \mathrm{D}_{0} \rightarrow{ }^{7} \mathrm{~F}_{1}$ transition is responsible for only one peak in the spectra. These results suggest the presence of a uniform chemical environment around the $\mathrm{Eu}^{3+}$ ion. It can be seen in Table 4 that the $0.03 \mathrm{~mol} / \mathrm{L}$ wood sample has the strongest emission intensity among all the modified samples.

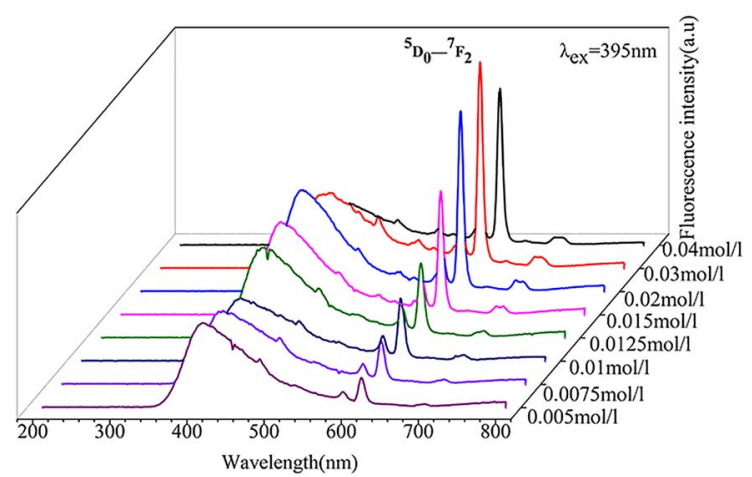

Figure 8. Emission spectra of different concentration

\subsubsection{Effect of reaction time}

In order to investigate the effect of different reaction times on the modified fluorescent wood, the reaction temperature and impregnation ratio were maintained at constant values.

As shown in Table 5, the fluorescence emission intensity at $619 \mathrm{~nm}$ increased firstly and then decreased with an increase in the reaction time. Over time, the product on the surface of the wood gradually increased in quantity. After $10 \mathrm{~h}$, the modified complex reacted completely with wood and the measured fluorescence emission intensity increased gradually. Therefore, the optimum reaction time for synthesizing modified fluorescent wood was determined to be $8 \mathrm{~h}$ (see the Fig. 9).

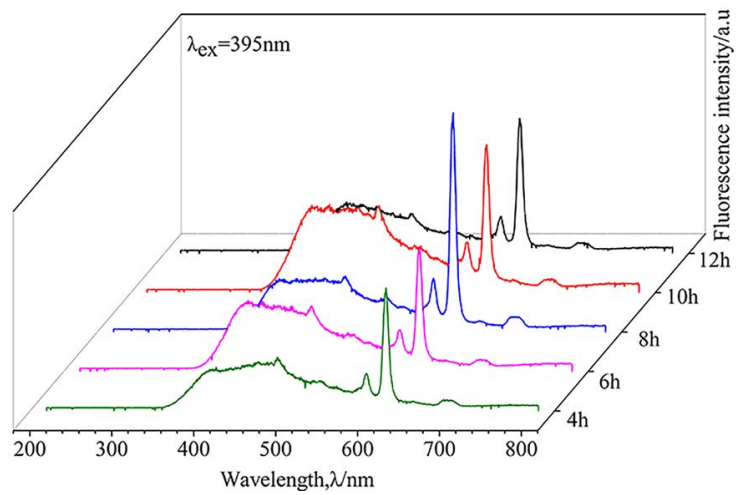

Figure 9. Emission spectra of different time

\subsubsection{Effect of reaction temperature}

With an increase in the reaction temperature, the fluorescence intensity of the modified wood samples increased. As shown in Table 6, an increase in temperature is beneficial for accelerating the reaction rate, resulting in a stronger fluorescence emission. The boiling point of absolute ethanol is $78.5^{\circ} \mathrm{C}$, beyond which the reaction temperature cannot be increased. Under such conditions, the emission intensity of the wood sample at $75^{\circ} \mathrm{C}$ was found to be the strongest (see the Fig. 10).

Table 4. Fluorescence intensity of modified fluorescent wood at different reaction concentration

\begin{tabular}{lcccccccc}
\hline Number & 1 & 2 & 3 & 4 & 5 & 6 & 7 & 8 \\
\hline Samples concentration $\left(10^{-1} \mathrm{~mol} / \mathrm{L}\right)$ & 0.05 & 0.075 & 0.1 & 0.125 & 0.15 & 0.2 & 0.3 & 0.4 \\
Fluorescence intensity (I/arb.units) & 78.9 & 114.7 & 168.7 & 200.6 & 333.0 & 487.3 & 557.2 & 422.4 \\
\hline
\end{tabular}

Table 5. Fluorescence intensity of modified fluorescent wood at different reaction times

\begin{tabular}{lccccc}
\hline Reaction time $(\mathrm{h})$ & 4 & 6 & 8 & 10 & 12 \\
\hline Fluorescence intensity (I/arb. units) & 210.9 & 237.5 & 354.2 & 196.2 & 196.2 \\
\hline
\end{tabular}

Table 6. Fluorescence intensity of modified fluorescent wood at different reaction temperatures

\begin{tabular}{lccccc}
\hline Reaction temperature $\left({ }^{\circ} \mathrm{C}\right)$ & 35 & 45 & 55 & 65 & 75 \\
\hline Fluorescence intensity (I/arb.units) & 109.6 & 124.3 & 172.9 & 208.0 & 235.8 \\
\hline
\end{tabular}




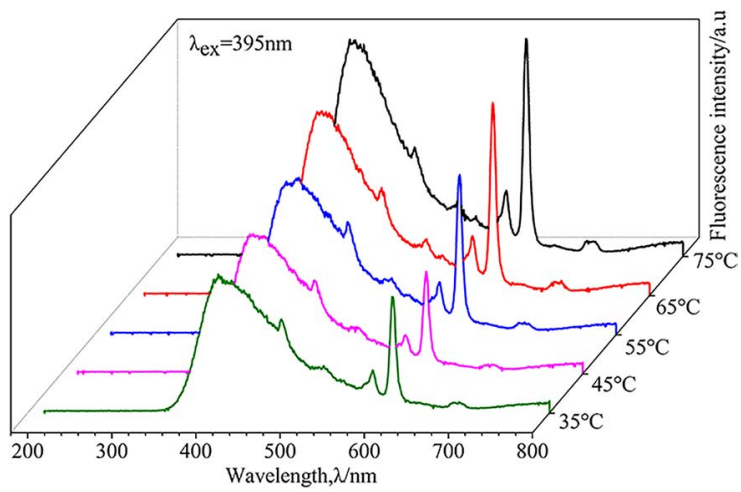

Figure10. Emission spectra of different temperature

\subsection{TG analysis}

The TG and differential thermogravimetry (DTG) curves of the native wood and modified fluorescent wood samples are depicted in Fig. 11. In the DTG curves, the first step could be attributed to the evaporation of water present in the wood samples. The second step in the pattern of poplar wood revealed a peak decomposition rate at around $270^{\circ} \mathrm{C}$, which was attributed to the degradation of wood components. However, modified fluorescent wood revealed a decomposition peak at $220^{\circ} \mathrm{C}$. This stage is attributed to the dehydration of $\mathrm{Eu}^{3+}$ complexes and wood components ${ }^{24}$. On comparing the TG results of samples with different impregnation ratios at $800{ }^{\circ} \mathrm{C}$, the mass loss of modified fluorescent wood was found to be around $86 \%$ and poplar wood almost completely decomposed. Moreover, the exothermic peaks of the modified fluorescent wood samples were observed to be weakened in the differential thermal analysis (DTG) curves, which indicates their good thermal stability ${ }^{25}$.

In order to confirm the percentage of $\mathrm{Si}$ and Eu that was deposited in the modified wood (Eu: phenanthroline: silane ligand=1:3:1), the test of this reside in EDX analysis could quantify the actual percentage of Si and Eu deposited, as shown in Fig. 12.

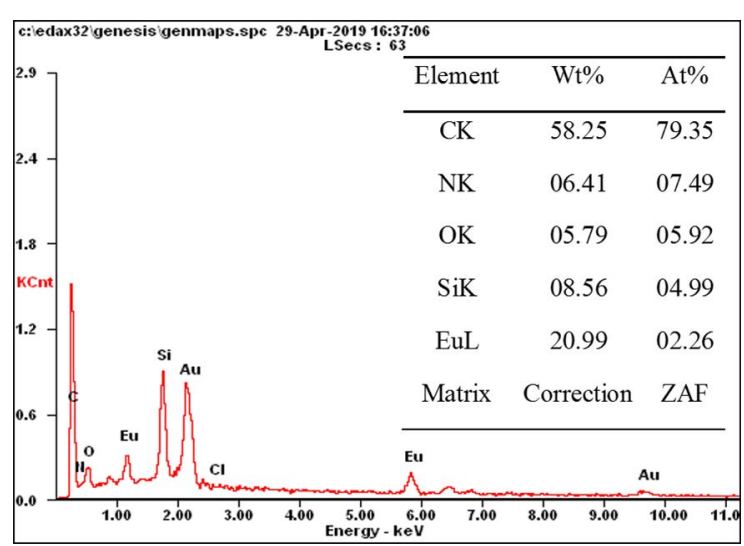

Figure 12. EDX analysis of residue modified wood (1:1:3)

Compared with Fig4(b), the chlorine in the residue disappears, mainly because the $\mathrm{C}-\mathrm{Cl}$ bond is destroyed under high temperature conditions, and the $\mathrm{Si}-\mathrm{N}$ of the silane coupling agent and 1,10-phenanthroline are also destroyed. The mass ratio of $\mathrm{C}, \mathrm{N}, \mathrm{O}$ and Eu elements in the modified wood residue decreased. The reside included $8.56 \% \mathrm{Si}$ and $20.99 \% \mathrm{Eu}$. The actual percentage of silicon and europium is 0.41 .

\subsection{Scanning electron microscopy}

The images in Fig. 13 show the SEM images of native and modified fluorescent wood samples. Fig. 13(a) and (b) show the native wood surfaces, including vessel architecture and pit hole morphology. Fig. 13(c) shows that the microscopic details of the pit holes were covered. Fig. 13(d) indicates a relatively smooth surface for modified fluorescent wood. In contrast, a dense-packed layer and a smooth vessel inner wall were observed on the surfaces of modified fluorescent wood. The filling up of the crevices shows that the modified complex reacted with the $-\mathrm{OH}$ groups on the surface of wood and adhered to it.
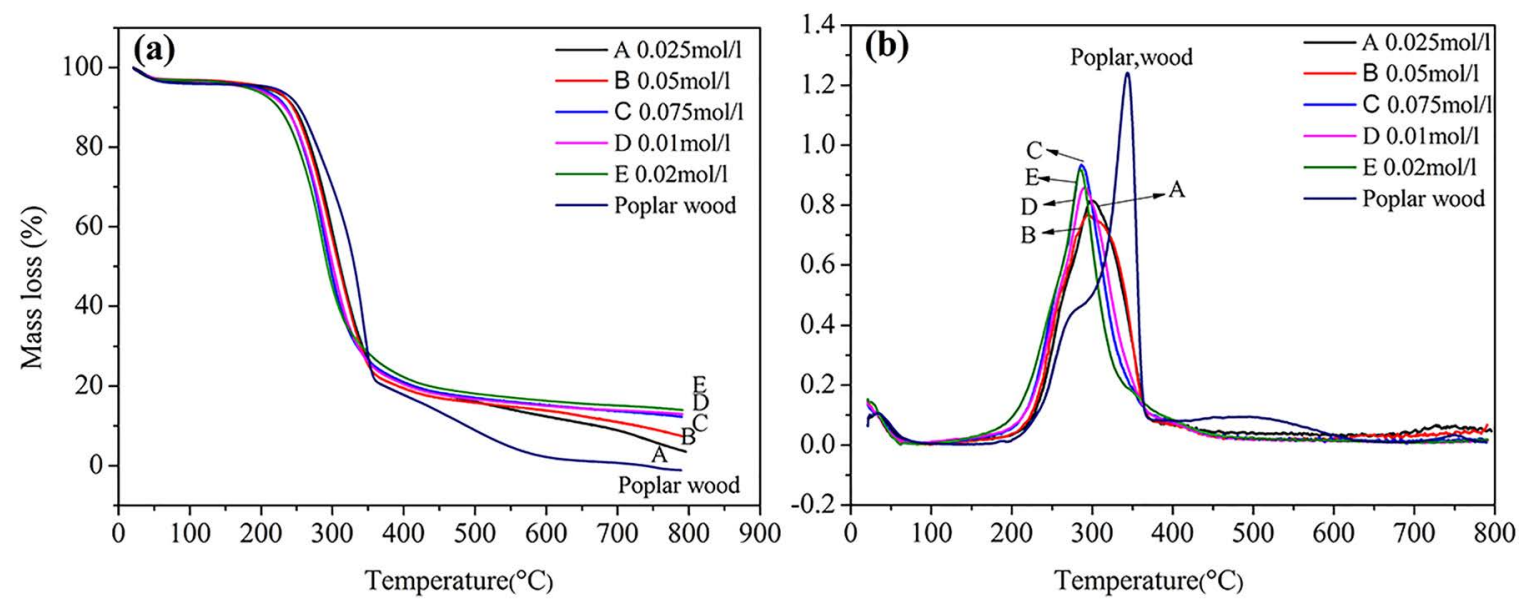

Figure 11. (a)TG/(b)DTG curves of different impregnation ratio of the wood 


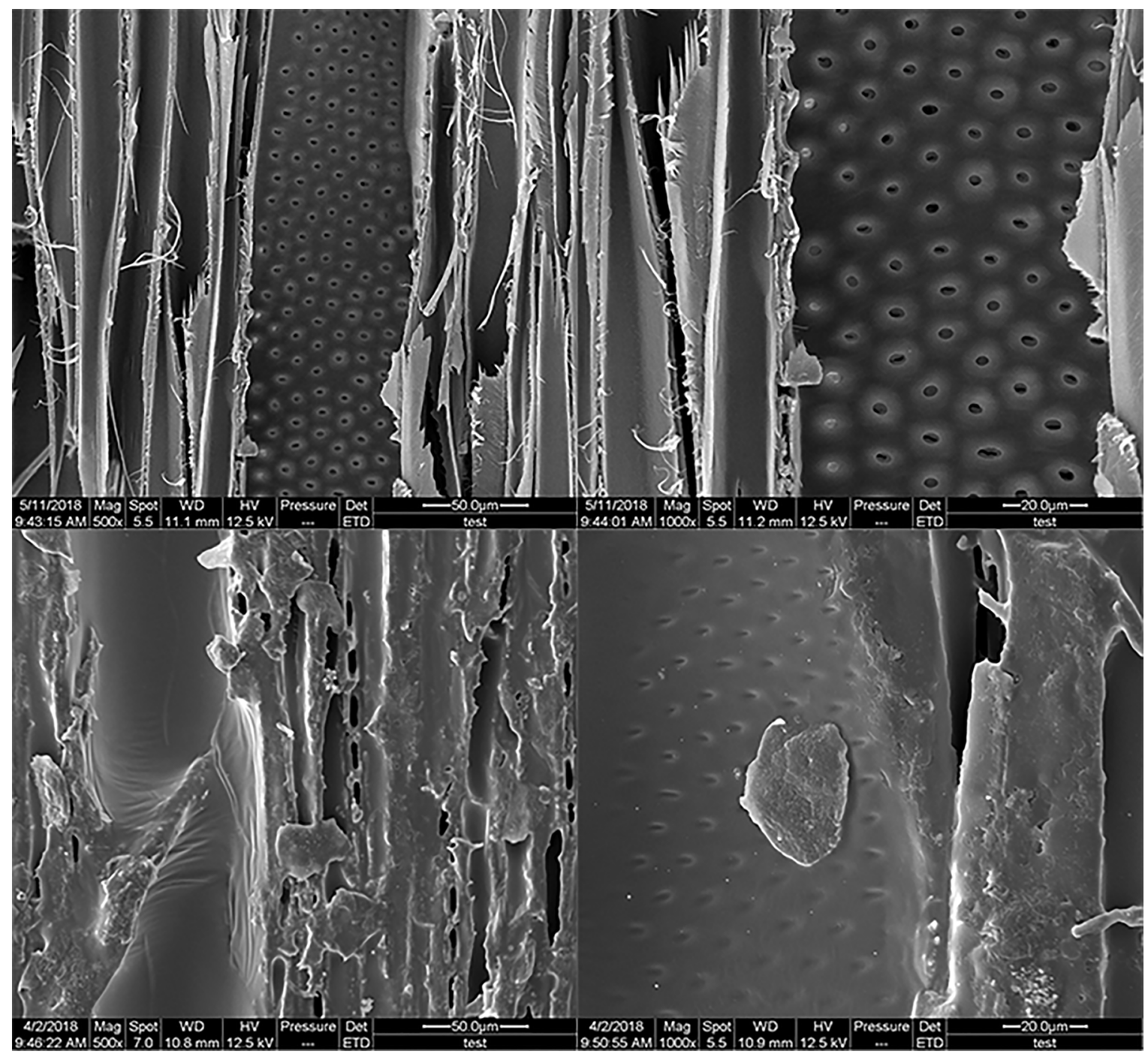

Figure13. SEM images of vertical section of different samples (a), (c) vessel of native wood and modified fluorescence wood $(\times 500)(b)$, (d) pit hole of native wood and modified fluorescence $\operatorname{wood}(\times 1000)$

\subsection{Fluorescence stability}

As shown in the Fig.14, the 1:3:1 modified wood was irradiated with 310nm UV lamps for $0 \mathrm{~h}, 24 \mathrm{~h}, 48 \mathrm{~h}, 72 \mathrm{~h}$, $96 \mathrm{~h}, 120 \mathrm{~h}$, respectively. When the aging time reached 24 $\mathrm{h}$, the fluorescence intensity of the wood fluctuates within a certain range. This shows that fluorescent wood has a strong ultraviolet absorption capacity and can continuously emit light under the excitation of ultraviolet light. This property can reduce the loss of wood due to ultraviolet light and prolong its life. On the other hand, it realizes the application of fluorescent wood in anti-counterfeiting and art exhibits.

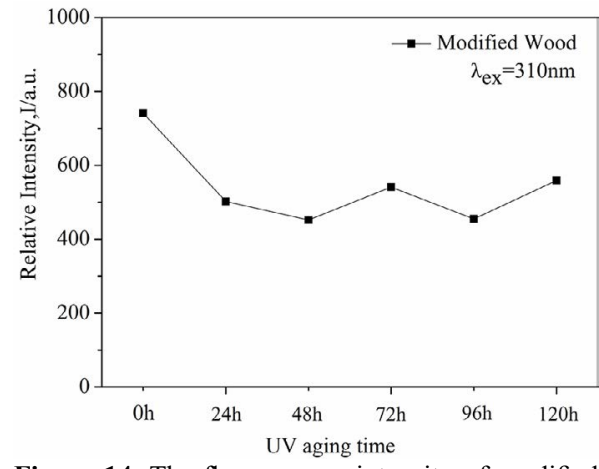

Figure 14. The fluorescence intensity of modified wood with different UV aging times 


\section{Conclusions}

Fluorescent wood was synthesized from native wood by modification with rare earth $\mathrm{Eu}^{3+}$ ternary complexes. The optimized reaction conditions were determined by measuring the fluorescence emission intensity of $\mathrm{Eu}^{3+}$; they were as follows-reaction time of $8 \mathrm{~h}$, reaction temperature of $75^{\circ} \mathrm{C}, \mathrm{Eu}^{3+}: 1,10$-phenanthroline:modified silane ligand ratio of $1: 1: 3$, and reactant concentration of $0.03 \mathrm{~mol} / \mathrm{L}$. The strongest fluorescence emission intensity of 557 arb.units was assigned to the ${ }^{5} \mathrm{D}_{2}{ }^{-} \mathrm{F}_{0}$ transition of $\mathrm{Eu}(\mathrm{III})$ ion in the fluorescence spectrum. The results of IR, XPS, and EDX analyses indicate that modified complexes on the surface of the wood. It has been proposed that the $\mathrm{Si}-\mathrm{OH}$ groups of the silane coupling agent link with the surface of wood. Compared to untreated wood, fluorescent wood exhibited better thermal properties and hydrophilicity.

The synthesized fluorescent wood can be used to construct new wood-based materials. Due to the presence of europium complexes, fluorescent wood samples can glow with a reddish photoluminescence. The application of such fluorescent wood will extend the usable life of poplar and prevent wood structural units from being destroyed by UV light. Further, such fluorescent woods not only enhance resource use and the efficiency of short wood, but also play an important role in anti-counterfeiting efforts.

\section{Acknowledgements}

This study was supported by the financial supports from the National Natural Science Foundation of China (GN:31770593) and the Fundamental Research Funds for the Central Universities (GN: 2572017CB18).

\section{References}

1. Jiang F, Li T, Li Y, Zhang Y, Gong A, Dai J, et al. Wood-Based Nanotechnologies toward Sustainability. Advanced Materials. 2017;30(1):1703453.

2. Cabane E, Keplinger T, Merk V, Hass P, Burgert I. Renewable and Functional Wood Materials by Grafting Polymerization Within Cell Walls. Chemsuschem. 2014;7(4):1020-1025.

3. Shwetha M, Eraiah B. Influence of europium $\left(\mathrm{Eu}^{3+}\right)$ ions on the optical properties of lithium zinc phosphate glasses. IOP Conference Series: Materials Science and Engineering. 2018;310(1):012033.

4. Paris O, Fritz-Popovski G, van Opdenbosch D, Zollfrank C. Recent Progress in the Replication of Hierarchical Biological Tissues. Advanced Functional Materials. 2013;23(36):44084422 .

5. Zhang X, Lv L, Qin Y, Xu M, Jia X, Chen Z. Removal of aqueous $\mathrm{Cr}(\mathrm{VI})$ by a magnetic biochar derived from Melia azedarach wood. Bioresource Technology. 2018;256:1-10.
6. Wang C, Cheng P, Lucas C. Synthesis and characterization of superhydrophobic wood surfaces. Journal of Applied Polymer Science. 2011;119(3):1667-1672.

7. Wu YQ, Jia SS, Wang S, Qing Y, Yan N, Wang QH, et al. A facile and novel emulsion for efficient and convenient fabrication of durable superhydrophobic materials. Chemical Engineering Journal. 2017;328:186-196.

8. Kostova MH, Batentschuk M, Goetz-Neunhoeffer F, Gruber $\mathrm{S}$, Winnacker A, Greil P, et al. Biotemplating of BaFBr:Eu ${ }^{2+}$ for X-ray storage phosphor applications. Materials Chemistry \& Physics. 2010;123(1):166-171.

9. Li X, Shen G, Jin X, Liu M, Shi L, Lu J. Novel polyimide containing 1,10-phenanthroline and its europium(III) complex: synthesis, characterization, and luminescence properties. Journal of Materials Science. 2016;51(4):2072-2078.

10. van Opdenbosch D, Kostova MH, Gruber S, Krolikowski S, Greil P, Zollfrank C. Replication of wood into biomorphous nanocrystalline $\mathrm{Y}_{2} \mathrm{O}_{3}: \mathrm{Eu}^{3+}$ phosphor materials. Wood Science \& Technology. 2010;44(4):547-560.

11. Xu QJ, Wang D, Ren SX, Fang G. Investigation on preparation and properties of wood-based luminescent materials modified by europium aromatic diacyl complexes. Journal of Functional Materials. 2015;Suppl 2:135-140.

12. Rojo E, Alonso MV, Del Saz-Orozco B, Oliet M, Rodriguez F. Optimization of the silane treatment of cellulosic fibers from eucalyptus wood using response surface methodology. Journal of Applied Polymer Science. 2015;132(26):42157.

13. Li S, Xie H, Zhang S, Wang X. Facile transformation of hydrophilic cellulose into superhydrophobic cellulose. Chemical Communications. 2007;46:4857-4859.

14. Yamanaka M, Sada K, Miyata M, Hanabusa K, Nakano K. Construction of superhydrophobic surfaces by fibrous aggregation of perfluoroalkyl chain-containing organogelators. Chemical Communications. 2006;21:2248-2250.

15. Xiao B, Sun XF, Sun RC. The chemical modification of lignins with succinic anhydride in aqueous systems. Polymer Degradation \& Stability. 2001;71(2):223-231.

16. Popescu CM, Popescu MC, Vasile C. Characterization of fungal degraded lime wood by FT-IR and 2D IR correlation spectroscopy. Microchemical Journal. 2010;95(2):377-387.

17. Singhal A, Jaiswal PK, Thakur IS. Biopulping of bagasse by Cryptococcus albidus, under partially sterilized conditions. International Biodeterioration \& Biodegradation. 2015;97:143-150.

18. Zhang M, Wang C. Fabrication of cotton fabric with superhydrophobicity and flame retardancy. Carbohydrate Polymers. 2013;96(2):396-402.

19. Krishnakumar V, Xavier RJ. FT Raman and FT-IR spectral studies of 3-mercapto-1,2,4-triazole. Spectrochimica Acta Part A: Molecular \& Biomolecular Spectroscopy. 2004;60(3):709-714.

20. Xu J, Zhang L, Shi R, Zhu Y. Chemical exfoliation of graphitic carbon nitride for efficient heterogeneous photocatalysis. Journal of Materials Chemistry A. 2013;1(46):14766-14772. 
21. Bala M, Kumar S, Taxak VB, Boora P, Khatkar SP. Synthesis, photoluminescent features and intramolecular energy transfer mechanism of europium (III) complexes with fluorinate $\beta$-diketone ligand and auxiliary ligands. Journal of Fluorine Chemistry. 2015;178:6-13.

22. Chen PL, Ma XY, Yang D. ZnO:Eu thin-films: Sol-gel derivation and strong photoluminescence from ${ }^{5} \mathrm{D}_{0} \rightarrow{ }^{7} \mathrm{~F}_{0}$ transition of $\mathrm{Eu}^{3+}$ ions. Journal of Alloys and Compounds. 2007;431(1-2):317-320.
23. Li FH, Liu H, Wei SL, Sun W, Yu LX. Photoluminescent properties of $\mathrm{Eu}^{3+}$ and $\mathrm{Tb}^{3+}$ codoped $\mathrm{Gd}_{2} \mathrm{O}_{3}$ nanowires and bulk materials. Journal of Rare Earths. 2013;31(11):1063-1068.

24. Zhou M, Zang D, Zhai X, Gao Z, Zhang W, Wang C. Preparation of biomorphic porous zinc oxide by wood template method. Ceramics International. 2016;42(9):10704-10710.

25. Gan WT, Xiao SL, Gao L, Gao R, Li J, Zhan X. Luminescent and Transparent Wood Composites Fabricated by Poly(methyl methacrylate) and $\gamma-\mathrm{Fe}_{2} \mathrm{O}_{3} @ \mathrm{YVO}_{4}: \mathrm{Eu}^{3+}$ Nanoparticles Impregnation. ACS Sustainable Chemistry \& Engineering. 2017;5(5):3855-3862. 